\title{
Hip Hop as an Agent for Health and Wellbeing in Schools:
}

\section{A Narrative Synthesis of Existing Research}

\author{
Alexander Hew Dale Crooke ${ }^{1 *}$, Rachael Comte ${ }^{2}$, Cristina Moreno Almeida ${ }^{3}$ \\ 1 University of Melbourne, Australia \\ 2 Parkville College Melbourne, Australia \\ 3 King's College London, Great Britain \\ *crookea@unimelb.edu.au
}

Received: 26 June 2019 Accepted: 14 January 2020 Published: 1 March 2020

Editor: Melody Schwantes Reviewers: Viggo Krüger, Adenike Webb

\begin{abstract}
Hip Hop culture has shown an increasing presence in mainstream schooling over the last 15 years. This presence has taken many forms, including extracurricular programs, pedagogical tools, and whole-school approaches to student learning and development. Yet, discourse explicitly exploring the use of Hip Hop to facilitate wellbeing outcomes in schools remains limited. To explore the state of current research at this particular intersection, this paper presents a narrative synthesis of 22 research articles reporting on the use of Hip Hop interventions for wellbeing in school settings. Results indicated a growing rate of published research articles in this area, focus on health promotion for underprivileged students of colour in urban US settings, and the need for more methodologically sound research which critically engages with socio-political contexts. Nevertheless, important benefits were reported across studies, demonstrating the value of Hip Hop in promoting across the physical, social and mental wellbeing of students.
\end{abstract}

Keywords: Hip Hop, student wellbeing, Hip Hop interventions, school programs, narrative synthesis

\section{Introduction}

Hip Hop's role in education settings has received significant attention in recent decades. Predominantly this has been related to pedagogical applications, both as a way to engage students, and as an educational discourse that aligns closely with critical pedagogies (Petchauer, 2009). Scholars maintain that it is the nature of Hip Hop culture that affords such potential, given it contains distinct modalities of practice that offer different ways of interacting with the world (Seidel, 2011), and it is built on discourse of resistance and critical consciousness that preferences knowledge (Hill \& Petchauer, 2013). 
Hip Hop is also considered one of the most important and influential popular cultures of our contemporary global society, and thus offers an important point of engagement for young people from most backgrounds (Elligan, 2004). Further, given its socio-historical foundations are built on both resisting oppression and celebrating community, this process of engagement can be seen to foreground inclusion and diversity, rather than perpetuating structural disadvantage (Alim, 2007). Such factors are considered by many as critical for pursuing social justice through education in the $21 \mathrm{st}$ Century (Ladson-Billings, 2015).

Hip Hop culture, and specifically Hip Hop (or Rap) music, have also gained increasing attention in discourses of individual and social wellbeing. In the last two decades, several important books have been published which outline how Hip Hop music offers important affordances in areas such as music therapy (Hadley \& Yancy, 2012) and social work (Travis, 2016). These and a growing number of academic texts cite the aspects of Hip Hop culture noted above as similarly valuable when working with wellbeing, whilst also identifying characteristics of the music and music making processes as particularly well suited to promoting wellbeing at both individual and community levels. Yet, despite the increase in published research exploring educational and wellbeing applications, studies specifically investigating wellbeing benefits of Hip Hop in school settings are lacking in both volume and rigor.

This narrative synthesis aims to address this gap by providing a consolidated overview and analysis of the research that has been published in this area and establish a core knowledge base for future enquiry to better understand how and when Hip Hop can promote wellbeing in schools. We also believe the analysis will be especially valuable for creative arts therapists and music therapists in particular; not only does it demonstrate how Hip Hop-based arts activities are already being used in schools to promote wellbeing, it also indicates the populations Hip Hop has been considered relevant for and offers recommendations for those wanting to integrate Hip Hop into their own practice. We hope this both promotes the use of Hip Hop in school settings, helps music therapists identify areas of relevance for their own work, and encourages critical reflection when engaging with the culture.

\section{Positionality of Authors}

To promote reflexivity, we offer the following statements to disclose our own personal and professional relationships to Hip Hop. This aims towards transparency in our positionality to and preunderstanding of Hip Hop culture and the impact of any potential conflicts in interest that these positions may have on our analysis.

The first author is a white, cis-gendered male living in Australia, who is a long-time fan of Hip Hop music and has been a DJ and beat maker for approximately 20 years. After experiencing wellbeing benefits from engaging with Hip Hop culture on a personal level, he has actively sought to promote recognition for its potential in music therapy and educational settings, and regularly engages in advocacy work through research, teaching and public speaking. He acknowledges this professional and personal relationship may influence certain research choices and foci in terms of results. Yet, he also regularly advocates for critical interrogations with how Hip Hop is applied and discussed in institutional settings and suggest his relationship with Hip Hop may offer valuable insight to pursue such a critical position here.

The second author's interest in Hip Hop emerged through working in a youth justice setting with young men aged between 15-22. Whilst working with these young people, she became particularly interested in both the transformative power of Hip Hop and the need to engage with it critically as a white Australian female who exists completely outside of this culture. This research paper is her first exploration of literature investigating the use of Hip Hop in schools, and she has sought to actively balance her belief in the value of Hip Hop for wellbeing, and her recognition for the need to be critical when exploring benefits. 
Author 3 has investigated rap music and Hip Hop culture for nearly a decade. She grew up listening to Cuban rap and also became a fan of North African rap. She has lived in Morocco for over five years where she actively contributed to the Hip Hop scene by organising concerts and public debates, as well as through cultural programs including one which brought together Colombian and Moroccan rappers. Her involvement in Hip Hop culture accounts for her interest in looking at the effects of Hip Hop in youth wellbeing, however, she carries out this work critically. Coming from a Cultural Studies approach, her research on the historical, economic, social and political dimensions of Hip Hop provides a holistic understanding of youth culture. While her knowledge and interest on the topic could suggest an inclination to portray the relationship between Hip Hop and wellness positively, her research provides a background with which to be aware of the inclinations in the field of music therapy to pivot around the relationship between music and wellbeing.

\section{Methods and Research Design}

This paper uses existing research to narrate the story of how Hip Hop has been used as an agent for wellbeing in schools. This process is guided by two main research questions:

- How has Hip Hop been used to address wellbeing in schools?

- What are the reported wellbeing benefits of Hip Hop in schools?

This synthesis aims to provide a summary of the different ways Hip Hop is understood to relate to wellbeing in schools. Popay et al. (2006) state narrative syntheses appropriate when reviewing bodies of research that use diverse approaches and methodologies. In such cases, providing a narrative of existing literature enables authors to tell the story of a particular field of study, offering "a summary of the current state of knowledge in relation to a particular review question" (Popay et al., 2006, p. 6). Here, the goal was to identify the underlying rationales for employing Hip Hop, and the different programs and/or approaches used to do so. Additional to providing a general overview, or "state of play," this analysis intends to identify strengths and shortcomings of existing practice and research in this area, thus providing a reference point for future work.

This narrative synthesis took a more flexible approach than traditional (i.e. systematic) reviews, which authors suggest is necessary when integrating and synthesising research from different disciplines and which use diverse methodologies (Greenhalgh et al., 2005). Nevertheless, this process did follow a methodical approach following guidelines for narrative syntheses proposed by Popay et al. (2006). This included identifying eligibility criteria for the inclusion of literature, systematic searching of specific databases, extracting data, and a consistent analysis procedure.

\section{Selection criteria}

Only literature which investigated how a specific Hip Hop-related activity supported student wellbeing in schools was included. Thus, only studies exploring activities within formal primary or secondary school settings (i.e. on school grounds) were included. Studies in pre-school, tertiary, or community settings were excluded. Hip Hop-related activities were defined as those specifically linked to Hip Hop culture, including:

- MC-ing, and/or listening to, performing, or composing raps or Hip Hop-based lyrics;

- DJ-ing, and/or listening to, performing, or composing Hip Hop music;

- Breaking and/or participating in dance described as being related to Hip Hop; or

- Graffiti and/or any visual art activity described as being related to Hip Hop.

The definition of wellbeing included physical, psychological, and social domains to capture the range of potential programs and interventions. Only studies reporting on a change (or lack thereof) in wellbeing using a methodological approach were included. 
Only academic, peer-reviewed, English language journal articles were included. A full list of the databases and dates searched through is provided in Table 1.

\section{Search process}

Initial searches were used the following terms and search logic: "Hip Hop" and "School" and "Wellbeing" or "Well-being" or "Well Being". Later searches included: "Hip Hop" or "Hip-Hop" or "HipHop" or "Rap" and "Health" or "Wellbeing" or "Well being" or "Well-being" or "Quality of life" or "Therapy" or "Counseling or "Counselling" and "School" or "Education" or "Classroom" or "Student" or "Class".

\section{Study selection process}

Abstracts of selected articles were read to ensure they reported on research and identified search terms referred to the concepts of interest. If this could not be established via the abstract, a search of the full text was conducted.

Common exclusions at this stage included the use of: "class" as a sociological construct, i.e. "working class"; RAP as an acronym for programs unrelated to Hip Hop culture, i.e. "resourceful adolescent program" (Shochet et al., 2001); Hip Hop in a program name where activities were unconnected to Hip Hop culture, i.e. "Hip Hop to Health Jr." (Fitzgibbon et al., 2006); Hip Hop activities mentioned as possible future interventions but not investigated in current study (Thompson, 2009); studies looking only at Hip Hop/Rap as a predictor of health outcomes or risky health behaviours were excluded (Johnson-Baker, Markham, Baumler, Swain, \& Emery, 2016; Tanner, Asbridge, \& Wortley, 2009).

Literature exploring pedagogical and socio-political topics related to critical literacies, culture, race, gender, and identity, but which did not explicitly report wellbeing outcomes, were also excluded. This proved a complex distinction to maintain given close relationships between wellbeing and constructs such as culture, identity, race, and pedagogy. Nevertheless, it was considered necessary to maintain this separation to differentiate between the vast body of literature exploring Hip Hop and Rap in a pedagogy context, but which preferences educational and/or social theory over empirical investigations of wellbeing. This study selection process resulted in a total of 34 papers that were included in the synthesis. More information on the study selection process is provided in Figure 1.

\section{Data extraction process}

Data from the final 22 papers were extracted using four categories: descriptive data (year published; field/discipline; country and; forms of Hip Hop studied); study design (wellbeing constructs studied; intervention type; setting; participant/population details; methodology); theoretical position (description of Hip Hop; rationale for using Hip Hop; theoretical approaches); and results (outcomes; key conclusions/recommendations). Data regarding study quality were also extracted to help interpret and analyse data.

\section{Analysis procedure}

Data extracted for each category were explored to look for patterns both within and between categories, enabling us to organise data for further analysis relevant to the research questions and capture emergent themes. During write up, authors regularly checked the literature again to ensure emerging themes or ideas were grounded in the data. 
Table 1

Databases Searched by Date

\begin{tabular}{|c|c|}
\hline Date Search Conducted & Index/Database \\
\hline $15 / 5 / 2017$ & Discovery (University of [xxx] Library Search Engine) \\
\hline $15 / 5 / 2017$ & EBSCO Host \\
\hline $15 / 5 / 2017$ & Academic Search Complete \\
\hline $16 / 5 / 2017$ & America: History \& Life \\
\hline $16 / 5 / 2017$ & CINAHL Complete \\
\hline $16 / 5 / 2017$ & Education Research Complete \\
\hline $16 / 5 / 2017$ & ERIC \\
\hline $16 / 5 / 2017$ & Family \& Society Studies Worldwide \\
\hline $16 / 5 / 2017$ & SOCINDEX \\
\hline $16 / 5 / 2017$ & Music Index \\
\hline $16 / 5 / 2017$ & MEDLINE \\
\hline $16 / 5 / 2017$ & Humanities International Complete \\
\hline $16 / 5 / 2017$ & Art Index Retrospective (H.W. Wilson) \\
\hline $16 / 5 / 2017$ & Communication \& Mass Media Complete \\
\hline $16 / 5 / 2017$ & Ovid \\
\hline $16 / 5 / 2017$ & Proquest \\
\hline $23 / 5 / 2017$ & Web of science \\
\hline $24 / 5 / 2017$ & Joanna Briggs Inst. \\
\hline $24 / 5 / 2017$ & Cochrane Library \\
\hline $24 / 5 / 2017$ & CAIRSS for music \\
\hline $24 / 5 / 2017$ & JStor Library \\
\hline $24 / 5 / 2017$ & Science Direct \\
\hline $26 / 5 / 2017$ & Scopus \\
\hline $26 / 5 / 2017$ & Informit \\
\hline $3 / 6 / 2017$ & Taylor and Francis Online \\
\hline
\end{tabular}

\section{Results}

\section{Descriptive overview of the 22 articles}

\section{Study characteristics}

Data regarding year and country of publication (see Figure 2) showed that while there has been research in this area since at least 1995, most studies have been published in the last 10 years, with an trend towards increased publication of studies in recent years. Research has been concentrated in the US and to a lesser degree Australia. The only research paper published outside these two countries was undertaken in the Peoples' Democratic Republic of Lao ${ }^{1}$.

Programs overwhelmingly focused on "rap" as the primary medium (see Table 2), including lyric writing, analysis and exposure to "rap" songs or videos. The only other element reported as the program focus was "dance," 2 yet it often shared this focus with "rap." Four articles reported a more wholistic approach, centring three or more elements with explicit reference to Hip Hop culture. These were coded as using "culture" as a medium. Papers were also coded to explore the fields or disciplines in which studies were located. This considered factors such as journal, author affiliations, and 
Figure 1:

Study Selection Process

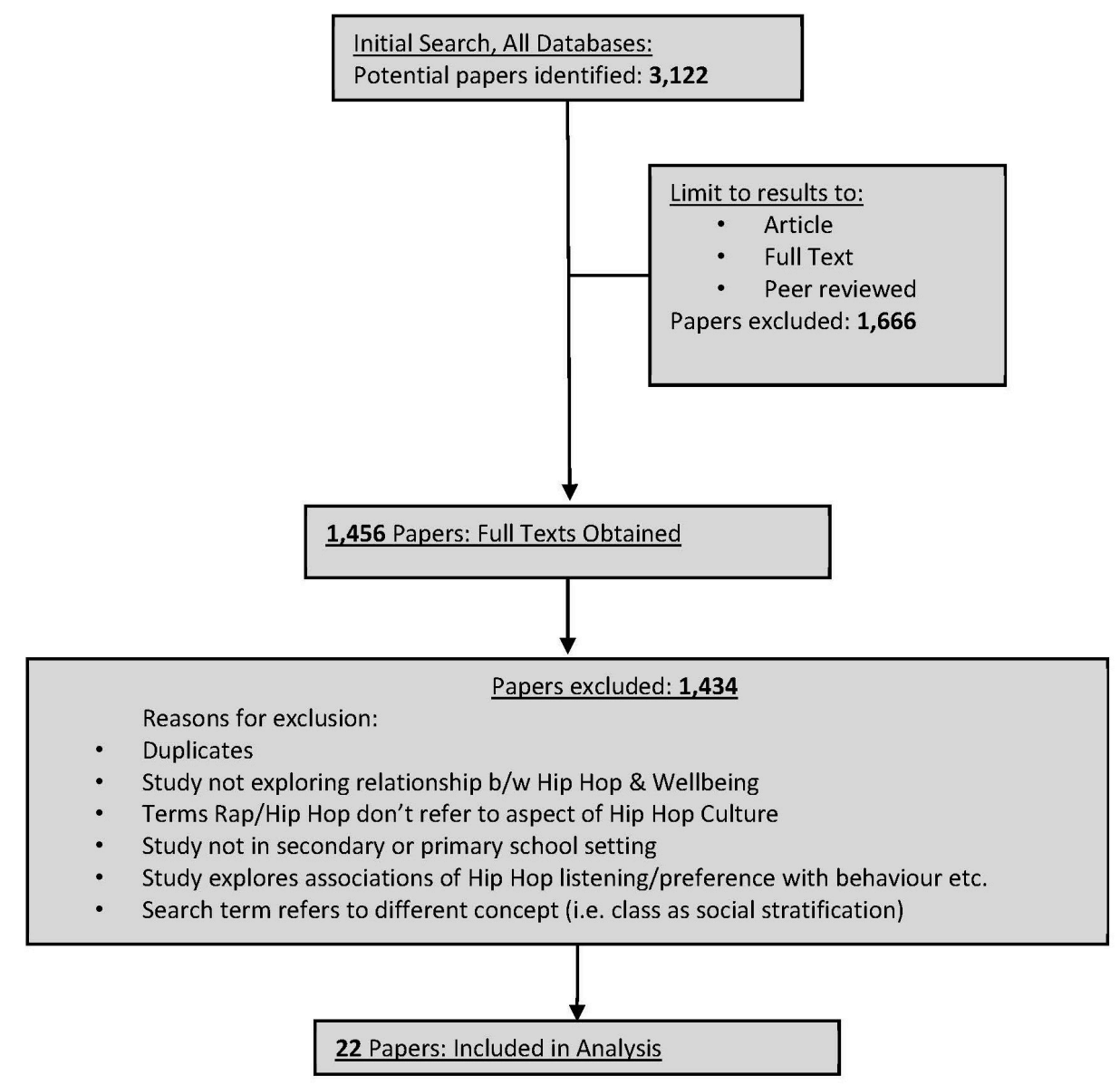

Figure 1

Study Selection Process

key theoretical constructs used. Coding revealed studies were overwhelmingly located in the "public health" category ( $n=14 ; 63.64 \%$ ), and included a range of associated fields such as community health, health prevention, health promotion, health intervention, population and social health, sexual health, and violence prevention. Some also included authors or theories from neurology, substance use and environmental health. These studies tended to focus on health awareness interventions, where the focus was on educating students about various health issues. Three $(13.64 \%)$ studies were located in the field of education and tended to focus on educational interventions, while the studies located in the fields of social work $(\mathrm{n}=3 ; 13.64 \%)$ and school counselling (n1; $4.55 \%$ ) focused specifically on therapeutic interventions. One paper was located specifically in the field of theatre $(4.55 \%)$ yet described a community arts program intervention approach.

\section{Settings}

US programs were predominantly located in urban, inner-city, or low-income neighbourhoods in large cities, such as New York, Philadelphia, Los Angeles, Atlanta, and Boston. Some studies were also located in more metropolitan and suburban areas, yet there was no mention of regional, rural, or remote settings. Conversely, Australian studies were located primarily in remote Aboriginal communities and to a lesser degree in suburban/outer-suburban areas. The study in Lao was located primarily in the city centre of Savannakhet. 
Publication Count by Year and Country

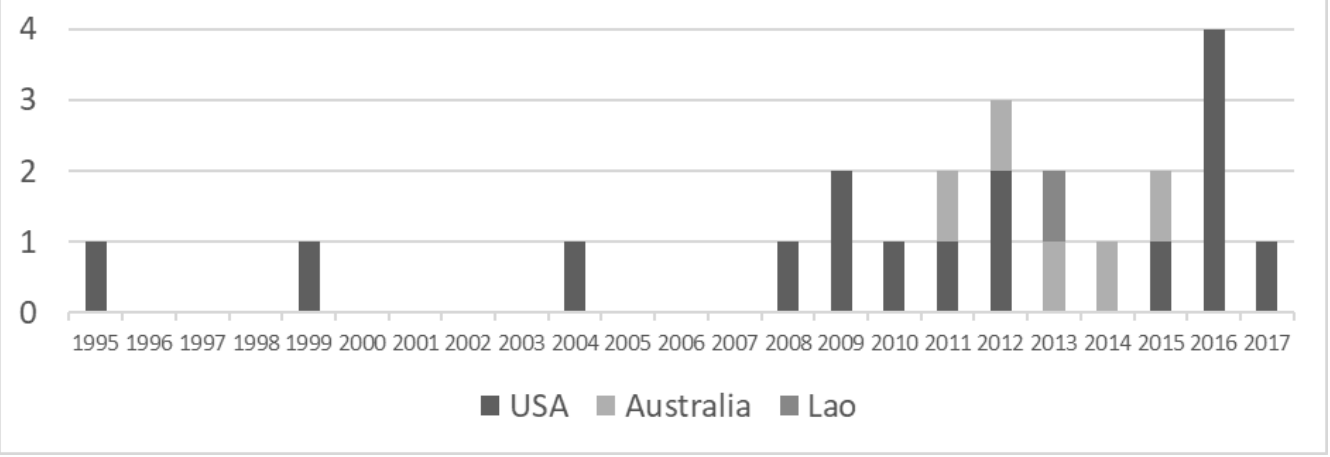

Figure 2

Number of Papers Published by Year and Country

Programs were primarily described as located in secondary/high schools $(\mathrm{n}=11)$, yet several were also in reported in primary/elementary $(\mathrm{n}=5)$, and junior high/middle school settings $(n=5)$. Of these, four were reported as being charter (Akintobi et al., 2011; Lamb \& Randazzo, 2016; Romero, 2012) or special schools for students with behavioural issues (Olson-McBride \& Page, 2012). Seven studies reported programs that were run in classroom settings, four in counselling settings within schools, and the rest were either after school programs, or a combination of school and community settings.

\section{Participant groups}

Study participants were mostly adolescents (aged 13-18 years). Those in primary/ elementary schools typically included students of 9 years and above. Only one study included students from kindergarten age (Criss et al., 2016). Several studies included students over 18, up to the ages of 23 (Hill, 2009), and 25 (McEwan, Crouch, Robertson, \& Fagan, 2013).

In US studies, participants were reported as being predominantly African American with several papers describing this as their main participant group (Akintobi et al., 2011; Gonzalez \& Hayes, 2009; Hill, 2009; Lamb \& Randazzo, 2016; Noble, Hedmann, \& Williams, 2015; Olson-McBride \& Page, 2012; Williams \& Noble, 2008). Students of Latino or Hispanic background (including Mexican/Mexican-American; Romero, 2012) were the next most represented group, followed by white, ${ }^{3}$ and Asian students. Other cultural backgrounds described included Native American (Akintobi et al., 2011), Pacific Islander and "mixed heritage" (Sussman et al., 1995). Tucker et al. (1999) did not explicitly report the cultural backgrounds of their participant group, yet suggest in their introduction a focus on addressing issues related to "African American youths", while Levy, Emdin, and Adjapong $(2017$, p. 3) described their participant group as "urban youth of color" (p. 3).

Australian studies located in remote communities reported their participants as being entirely (Crouch, Robertson, \& Fagan, 2011; McEwan et al., 2013) or predominantly (Ennis, Clark, \& Corfield, 2014) of Indigenous background - including Aboriginal and Torres Strait Islander. Another Australian study reported culturally and linguistically diverse participants, with a significant amount born in New Zealand, and speaking Samoan or Maori at home (Harris, Wilks, \& Stewart, 2012). Cultural background was not reported in the other Australian study (Paukste \& Harris, 2015). In the paper from Lao, participants were reported as being Laotian (Yoshida, Kobayashi, Sapkota, \& Akkhavong, 2013).

Participants in at least 13 studies were reported as coming from low-socioeconomic backgrounds. With the exception of one study (Yoshida et al., 2013) all participant 
Table 2

Articles Reviewed, and Descriptive Information

\begin{tabular}{|c|c|c|c|c|c|c|}
\hline Author & Year & $\begin{array}{l}\text { Primary } \\
\text { Discipline }\end{array}$ & Country & $\begin{array}{c}\text { Primary form of } \\
\text { Hip Hop }\end{array}$ & $\begin{array}{l}\text { Primary } \\
\text { Wellbeing } \\
\text { Construct }\end{array}$ & $\begin{array}{c}\text { Primary } \\
\text { intervention } \\
\text { type }\end{array}$ \\
\hline Sussman et al. & 1995 & Public health & USA & Rap & Substance use & Health awareness \\
\hline Tucker et al. & 1999 & Public health & USA & Rap & $\begin{array}{l}\text { Violence preven- } \\
\text { tion }\end{array}$ & Health awareness \\
\hline $\begin{array}{c}\text { DeCarlo \& Hock- } \\
\text { man }\end{array}$ & 2004 & Social work & USA & Rap & Pro-social skills & $\begin{array}{c}\text { Therapeutic in- } \\
\text { tervention }\end{array}$ \\
\hline Williams \& Noble & 2008 & Public health & USA & Rap & Stroke & Health awareness \\
\hline Hill & 2009 & Education & USA & Rap & $\begin{array}{l}\text { Psychosocial } \\
\text { wellbeing }\end{array}$ & $\begin{array}{l}\text { Educational in- } \\
\text { tervention }\end{array}$ \\
\hline Gonzalez \& Hayes & 2009 & $\begin{array}{l}\text { School coun- } \\
\text { selling }\end{array}$ & USA & Rap & Mental health & $\begin{array}{c}\text { Therapeutic in- } \\
\text { tervention }\end{array}$ \\
\hline $\begin{array}{l}\text { Boutin-Foster et } \\
\text { al. }\end{array}$ & 2010 & Public health & USA & Rap & Sexual health & Health awareness \\
\hline $\begin{array}{l}\text { Crouch, Robert- } \\
\text { son, \& Fagan }\end{array}$ & 2011 & Public health & Australia & Rap \& Dance & Sexual health & Health awareness \\
\hline Akintobi et al. & 2011 & Public health & USA & Rap & Sexual health & Health awareness \\
\hline $\begin{array}{l}\text { Harris, Wilks, \& } \\
\text { Stewart }\end{array}$ & 2012 & Public health & Australia & Dance & $\begin{array}{l}\text { Psychosocial } \\
\text { wellbeing }\end{array}$ & $\begin{array}{c}\text { Community arts } \\
\text { program }\end{array}$ \\
\hline Romero & 2012 & Public health & USA & Culture & Obesity & Health awareness \\
\hline $\begin{array}{c}\text { Olsen- McBride \& } \\
\text { Page }\end{array}$ & 2012 & Social work & USA & Rap & Mental health & $\begin{array}{l}\text { Therapeutic in- } \\
\text { tervention }\end{array}$ \\
\hline McEwan et al. & 2013 & Public health & Australia & Rap \& Dance & Sexual health & $\begin{array}{c}\text { Community arts } \\
\text { program }\end{array}$ \\
\hline Yoshida et al. & 2013 & Public health & Lao & Rap & Global & Health awareness \\
\hline $\begin{array}{c}\text { Ennis, Clark, \& } \\
\text { Corfield }\end{array}$ & 2014 & Theatre & Australia & Rap & $\begin{array}{l}\text { Psychosocial } \\
\text { wellbeing }\end{array}$ & $\begin{array}{c}\text { Community arts } \\
\text { program }\end{array}$ \\
\hline Paukste \& Harris & 2015 & Public health & Australia & Rap & Substance use & Health awareness \\
\hline $\begin{array}{c}\text { Noble, Hedmann, } \\
\text { \& Williams }\end{array}$ & 2015 & Public health & USA & Culture & Dementia & Health awareness \\
\hline $\begin{array}{c}\text { Emdin, Adjapong, } \\
\text { \& Levy }\end{array}$ & 2016 & Education & USA & Rap & Mental health & $\begin{array}{c}\text { Educational in- } \\
\text { tervention }\end{array}$ \\
\hline Lamb \& Randazzo & 2016 & Education & USA & Rap & Sexual health & Health awareness \\
\hline Williams et al. & 2016 & Public health & USA & Culture & Nutrition & Health awareness \\
\hline Criss et al. & 2016 & Public health & USA & Rap & Obesity & Health awareness \\
\hline $\begin{array}{l}\text { Levy, Emdin, \& } \\
\text { Adjapong }\end{array}$ & 2017 & Social work & USA & Culture & Mental health & $\begin{array}{l}\text { Therapeutic in- } \\
\text { tervention }\end{array}$ \\
\hline
\end{tabular}

groups were described as coming from communities at risk in areas of health disparity, violence, school disengagement, family instability, behaviour problems, and poverty.

No studies explicitly reported non-binary or gender-diverse student participants. Of those reporting gender, most studies included a relatively even mix of male and female participants. Two studies reported only male participants (DeCarlo \& Hockman, 2004; Gonzalez \& Hayes, 2009) and another explained a disproportionate ratio of female (134) to male (37) participants, because "adolescent females are more readily involved 
in 'artistic' or group school activities than adolescent males" (Harris et al., 2012, p. 241).

\section{Intervention approaches and constructs of wellbeing addressed}

The key intervention approaches reported in the 22 studies were interpreted as falling under the four main categories of Health Awareness, Educational Interventions, Community Arts Programs, and Therapeutic Interventions. These emerged as global categories by which the different studies could be described and are used here as a way to organize results regarding construct of wellbeing addressed, program content, key theoretical concepts used, and Hip Hop activities employed.

\section{Health Awareness}

The Health Awareness intervention approach was the most popular ( $\mathrm{n}=13 ; 59.1 \%$ ). This approach focuses on the use of Hip Hop to transmit health-related information to young people, and increasing their awareness of risk and protective factors around health issues. These studies were located entirely within the field of public health (and associated fields as described above), except one which was located within education (Lamb \& Randazzo, 2016). Invariably, these interventions sought to address physical constructs of wellbeing. This included four sexual health programs, which used: rap videos to deconstruct and discuss narratives of rape culture (Lamb \& Randazzo, 2016); analysis of lyrical content in popular rap videos to raise awareness around STIs (Boutin-Foster et al., 2010); lyric writing to augment a larger program promoting abstinence and positive sexual norms (Akintobi et al., 2011); and the creation, recording, and performance of rap songs promoting community-wide awareness of sexual health issues (Crouch et al., 2011).

Programs targeting aspects of healthy eating such as nutrition (Williams et al., 2016) and obesity (Criss et al., 2016; Romero, 2012) were also significant. Two of these took a wholistic approach to engaging Hip Hop, describing interventions which incorporated several aspects of the culture. For Williams et al. (2016) this involved transmitting information through Hip Hop culture-informed videos, cartoons, and rap songs. Similarly, Romero (2012) described use of breakdancing, graffiti, and rap writing workshops, as well as discussion of rap content and Hip Hop history to explore healthy eating themes. Another used video, song, and artwork creation to explore such themes, although the role of Hip Hop appeared less central (Criss et al., 2016).

Substance use was another focus, with one study using writing and performance of rap (amongst a number of tools) to raise awareness around risks of alcohol, tobacco, and other drug use (Paukste \& Harris, 2015), while another used receptive viewing of rap videos to prevent smoking uptake (Sussman et al., 1995). Two interventions sought to increase community knowledge more generally in areas of neurological disorders: one using receptive listening to a tailored hip-hop song to increase awareness and recognition of stroke symptoms; the other using a combination of Hip Hop culture-informed music, dance, cartoons, and comics to increase health literacy around Alzheimer's disease. Another explored the use of a rap music video, amongst other tools, to educate and expose students to the consequences of physical trauma for violence prevention (Tucker et al., 1999).

The only study investigating a Health Awareness approach, but not targeting a specific health construct, was Yoshida et al. (2013) who instead sought to develop and validate a scale which could determine the degree to which songs were able to communicate health promotion messages. This included a Laotian Hip Hop song, among two other traditional Laotian folk and strings-based songs.

Each of these studies focused on promoting awareness of health issues. Hip Hop was seen primarily as a tool to communicate information for this goal, and indicators of success included knowledge retainment and change in attitudes and beliefs. The connection between these programs and constructs of physical, rather than social or psychological, health was striking, and suggest a strong pattern in this area of research. 


\section{Educational Interventions}

The Educational Intervention approach can be described as the use of Hip Hop-related activities in pedagogical-focused programs to improve wellbeing. Two of the 22 papers $(9.09 \%)$ reported these kinds of interventions, both of which described a strong focus on psychosocial wellbeing, including mental health and social connectedness.

While Health Awareness interventions undeniably include a strong focus on educating students, and may include pedagogical elements, several key factors differentiated these from Educational Interventions. Most significantly, instead of using Hip Hop to deliver health-related information to students with the hope of improving future health outcomes, Hip Hop was described here as providing a space for students to explore issues related to their own lives, and in doing so improve their wellbeing in the moment. Furthermore, unlike Health Awareness interventions, which were often delivered in classes related to the construct of health being addressed (i.e. physical or sexual education), Educational Interventions occurred in curriculum areas not immediately associated with the constructs of wellbeing addressed. For example, Hill (2009) described a program that used Hip Hop texts to teach English in the school curriculum, indicating its inherent pedagogical nature. Yet, by using this setting to analyze Hip Hop texts that themselves provided a "democratic space," teachers were able to facilitate a space where students could explore their own narratives of pain, suffering, and injustice. This enabled students to share and connect with others with similar stories, express themselves, and form a sense of community.

Emdin, Adjapong, and Levy (2016) report on the benefits of a science program that used the composition of raps for "engaging in and with rigorous science content" (p. 308). While a primary intention and outcome of this program was to support student learning in the science curriculum, authors reported that through the act of writing and reflecting on their rhymes, students were able to express aspects of their life experiences and become more connected with their emotions. Again, conscious facilitation by teachers enabled a space where students could foster a sense of agency and social connection with their teachers and each other. They described this as "the merging of the 'first space' of traditional STEM education and the 'second space' of mental health/ counseling to create a third space where urban youths can release tensions that result from trauma they experience" (p. 310). These examples suggest that Educational Interventions depend less on the nature of the information being delivered and more on the spaces facilitated by teachers for students to engage with Hip Hop as a way to process their own experiences.

\section{Community Arts Programs}

Studies identified as taking a Community Arts Programs approach were characterized by interventions which were described as embedded within, delivered by, or closely linked with the wider community. Furthermore, it was not only the facilitation of the program that included the wider community, but benefits were also often intended to extend beyond the student participants to their respective communities. Three of the 22 (13.6\%) programs were identified in this category, all were located in Australia, and all involved a range of performing arts modalities to engage community.

Ennis et al. (2014) described a project that used theatre and music workshops to undertake what was described as a community development project. While this included a primary focus on supporting student confidence, self-esteem, and school engagement, it also aimed to create lasting relationships between schools, students, the local community, and community-based arts organizations. While the program included arts activities not related to Hip Hop (such as dance), the creation and production of Hip Hop songs (beats and lyrics) which were shared through music videos and performances were central. These were said to give Indigenous youth a voice in their communities and create connection between different social groups.

McEwan et al. (2013) described a similar project that included the creation and performance of Hip Hop dances and songs with Indigenous youth. While the primary 
goal was to promote sexual health, it involved other key aims and outcomes including "event-specific community mobilisation [and laying] important groundwork to progress school-based and community mechanisms to address regional youth disadvantage" (p. 132). Thus, while the project aimed to achieve immediate health outcomes, there was an equivalent focus on developing the capacity of the community to address health issues in the future. Authors described a specific focus on exploring the use of arts to facilitate community-driven approaches to address health issues, as an alternative to clinical interventions.

The program described by Harris et al. (2012) focused on the use of dance to address students' psychological, social, and physical wellbeing. Again, a central tenet of this program was to facilitate positive community connections. While students worked on their dances within school settings, final performances held between participating schools and in local community settings offered them ways to engage in "positive social activities within their community" (p. 239). Along with a range of more individual wellbeing outcomes related to physical health and confidence, students also reported stronger social ties in their district communities. This included positive connection to peers, their schools, and through collaboration and public performances, other schools, local institutions, family groups, and community more generally. These examples suggest a project-based intervention approach which uses Hip Hop activities carried out in community settings to not only address individual wellbeing but also to develop stronger communities.

\section{Therapeutic Interventions}

Programs identified as Therapeutic Interventions were unique in their use of Hip Hop specifically as a therapeutic tool. Four of the $22(18.2 \%)$ studies made up this category, all of which were located in therapeutic-related fields, such as social work or school counseling, and focused specifically on addressing psychosocial or mental health. Unlike the other approaches, these programs were delivered by qualified mental health professionals in controlled settings typically deemed appropriate for addressing and processing significant psychosocial or mental health issues. With the exception of one (Levy et al., 2017), all programs focused on the use of rap as a therapeutic tool.

For example, Olson-McBride and Page (2012) described a "specialized poetry therapy intervention that incorporated hip-hop and rap music with high-risk youths" (p. 124). While this program involved a poetry/creative writing element, the authors reported a significant focus on using analysis and discussion of popular rap songs to facilitate participants' self-disclosure of significant or traumatic life events, fears, fantasies, and relationship issues.

Gonzalez and Hayes (2009) described a school counseling intervention that is based on Elligan's (2004) model of Rap Therapy. Here a student's personal interpretation of lyrics and messages in rap songs were used to explore associations with their own thought patterns, emotions, and risky behaviours. Through facilitated discussion of these associations in the larger context of rap music, the counselor worked with the students to reframe anti-social or risky thoughts and behaviours. This intervention involved roleplay, as well as composition of rap lyrics, to explore more constructive thought processes as well as to express and process personal struggles.

DeCarlo and Hockman (2004) described an intervention where three groups of young men (one of violent offenders, one of status offenders, and one of non-offenders) analysed lyrics from popular rap songs to develop prosocial behaviors around "female gender abuse, anger management, impulse control, reasoning, morality, responsibility, [and] identity" (p. 52). While authors referred to this as psychoeducation program in the article, this program was categorized as a Therapeutic Intervention as it was otherwise described specifically as a therapy program, delivered by a trained clinical social worker in a therapeutic setting, and involved group processing of sensitive topics like those above. 
The program described by Levy et al. (2017) extended beyond a focus on rap, and centred instead on the concept of a "hip-hop cypher," which they described as "highly codified yet unstructured practices where youth who identify with hip-hop culture information exchange in the form of raps or dance" (p. 2). Here, while students engaged in a social work group program that involved DJing, writing raps, making beats, and recording full tracks, the concept of the hip-hop cypher was described as the central element, with the key social norms of the cypher used to help structure group sessions. These included,

(1) everyone stands equidistant from one another in a circle, (2) everyone has a chance to share, (3) all voices have equal value, (4) praise is awarded to individuals when they share, and (5) equal support is provided to participants when in need. (p. 4)

These sessions aimed to "enable students the opportunity to express and explore a multitude of emotional obstacles they were facing" (p. 3), while also allowing opportunities for them to form social support structures and community.

As these examples show, Therapuetic Intervnetions are more likely to target significant emotional, social and mental health issues of individuals, in a theraputic format. They also position themselves as largely separate from the mainstream curriculum and can be seen as less focused on community-wide engagement in order to allow more focus on addressing the issues affecting young people in the moment.

\section{Wellbeing benefits reported by intervention approach}

Overall, the included articles reported school-based Hip Hop programs led to noteworthy outcomes related to wellbeing in several key areas. For ease of reporting, these benefits are organized here by the Intervention Approaches described above.

\section{Health Awareness}

Wellbeing benefits reported in relation to Health Awareness interventions related primarily to health promotion, observed chiefly in terms of increased student awareness of health issues and conditions. This included increased knowledge of the symptoms and causes of Alzheimer's Disease (Noble et al., 2015) and stroke (Williams \& Noble, 2008), as well as the risks and choices related to sexually transmitted infections (STI) (Boutin-Foster et al., 2010). Akintobi et al. (2011) also reported a significant increase and retainment of student knowledge and understanding of the risks of sex, benefits of abstinence, as well as associated refusal skills and goal setting strategies.

Other studies also reported changes in attitude in behaviour. Paukste and Harris (2015) related their program was not only successful in engaging and informing hard to reach youth about the risks of substance abuse, it was also observed to change attitudes to use. Lamb and Randazzo (2016) stated the sexual ethics program they investigated successfully changed anti-woman and rape-conducive beliefs, as shown by significant positive changes on measures of rape myth beliefs and intent to act ethically on behalf of victims. Tucker et al. (1999) reported modest benefits in students' ability to retain information related to physical trauma, identify violence as a problem, and the deterrence of future violence. Williams et al. (2016) reported more specific changes in health-related behaviour, as demonstrated by a mean decrease of $20 \%$ in the students' purchase of high-calorie or unhealthy foods. Romero (2012) reported a wider range of benefits, including significant increase in vigorous, physical activity, increased self-esteem among girls, and decreased perceptions of neighbourhood-related health barriers for boys.

Some studies described engagement as a primary outcome. Criss et al. (2016) reported their media-competition program for the dissemination of obesity-related information showed a high adoption rate among schools (school 1, $100 \%$; school 2, 39 $\%$ ), and notable student reach (school 1, $30 \%$; school 2, $13 \%$ ). The performing arts program investigated by Crouch et al. (2011) was found effective in engaging both students and community members in exploring and discussing physical, emotional, 
and sexual health related issues and in developing strategies to address them. However, several studies in this category reported no benefits. For example, Sussman et al. (1995) found no observable benefits of a Hip Hop video on "intention to smoke" or "trial of smoking" measures, while students in Yoshida et al.'s (2013) reported a HipHop song less effective in communicating health messages than two traditional Laotian songs.

\section{Educational Interventions}

As mentioned above, studies of Educational Interventions reported benefits in the areas of psychosocial wellbeing and mental health. However, in both cases, these were described as linked to regular classroom practice.

For Hill (2009) benefits centred on disclosure and the concept of "healing" which,

Neither presumes nor suggests a completed [...] recovery. Rather, it refers to the process by which members [...] were able to find varying levels of insight, relief, support, empathy, and critique within the Hip-Hop Lit community for their personal and ideological wounds. (p. 274)

Specific benefits included self-expression and connection with others through narratives around pain, loss, marginalization, and inequity. This led to the ability to share and process experiences of pain and suffering and the formulation of a community, which provided social support and cohesion. Notably, Hill reported this did not benefit their wellbeing in isolation from the educational setting, but also helped students and teachers imagine new, culturally relevant possibilities for engaging in classroom spaces.

Emdin et al. (2016) also reported mental health benefits in connection to classroom practice and learning. These benefits included students' ability to gain deeper knowledge of themselves by engaging with, expressing, and sharing issues they face in their daily lives through lyric composition. In doing so, they were able to voice their emotions, and become more socially connected to others. Teachers were also able to gain insight into the socioemotional sides of their students. Authors reported educational benefits as inextricable from these emotional benefits; not only did their lyrical compositions contain science content, but they could re-imagine their identities as science students in positive ways.

\section{Community Arts Programs}

Benefits of Community Arts Programs interventions emerged as representing a mix between individualised psychosocial benefits, as well as broader community-related social outcomes. For example, while Harris et al. (2012) reported more individualized outcomes, including self-expression the ability to participate in positive life experiences, the socially-focused outcomes were significant. This included observed co-operation, social solidarity, and connectedness with school community. Similarly, while McEwan et al. (2013) reported increased awareness among students, own knowledge of sexual health and social disadvantage, benefits such as increased social connection, and social change in the form of community mobilization around sexual health issues were prominent.

Ennis et al. (2014) also reported both personal and social benefits. Personalised benefits included reduced shame and increased sense of pride, confidence, self-esteem, and school engagement. The provision of a uniquely safe space also facilitated social, connection, cohesion, and inclusion between different socioeconomic and ethnic groups, while the program in general facilitated students' connection to schools and the local community. 


\section{Therapeutic Interventions}

Studies of Therapeutic Interventions consistently reported profound psychosocial wellbeing outcomes. These centred on self-expression, catharsis, meaningful social connection, and self-management of emotions and behaviours. Levy et al. (2017) reported their counselling program provided students a space which offered a sense of safety and belonging, allowing students to create positive and cohesive group norms and ways of being together that were communal, open, and accepting. This space promoted self- and emotional-expression, and connection via sharing personal narratives. This offered opportunities for catharsis, and when combined with the established respectful and supportive environment, allowed students to unite, connect and affirm each other through mutual social support. A further outcome was that students became more open to counselling processes.

Gonzalez and Hayes (2009) described a young person who gained a broader understanding of rap music and re-assessed their connection with risky or anti-social lyrical content. Through writing and discussing their own raps, they were able to express, externalise, and process life experiences. This process allowed them to recognise and acknowledge their own anger and negative behaviours, and learn how to manage them in positive ways.

For Olson-McBride and Page (2012), benefits related primarily to self-disclosure through shared opportunities for prosocial interaction. While rates of self-disclosure often fluctuated, given students' perceived need to protect themselves from harm, exploration of song lyrics precipitated deeply personal discussions around individuals' thoughts and feelings. These discussions facilitated meaningful self-expression and prosocial relationships between group members. Authors described this as "therapeutic self-disclosure and connection", which not only allowed them to become more aware of each other, but also themselves.

DeCarlo and Hockman (2004) reported students' preference for a "RAP therapy" program over a psychoeducational program that contained no Hip Hop content. DeCarlo and Hockman go on to report those participating in the RAP therapy program showed better engagement during sessions and prosocial skills development than those in the psychoeducational program. Benefits in prosocial skills were most pronounced in areas of anger management; delinquent behaviour; impulse control; female gender abuse; moral development; decision making; social relations; and relatedness to daily life situations.

Studies in the Therapeutic Interventions category align most closely with music therapy practice. Thus, benefits reported here indicate the value of working through or with Hip Hop in school-based music therapy programs.

\section{Role and positioning of Hip Hop}

To rigorously explore the connection between wellbeing and Hip Hop in schools we found it necessary to analyse how authors positioned Hip Hop in relationship to their studies and reported outcomes. To do this we asked three main questions of the literature: how is Hip Hop described; what is was the rationale for using Hip Hop; and what was the connection between Hip Hop and the outcomes?

\section{Description and positioning of Hip Hop}

Authors took several different approaches to describing Hip Hop in the reviewed articles. These descriptions emerged under three categories; Hip Hop as Culture, Hip Hop as Genre or Activity, No Formal Description.

\section{Hip Hop as culture}

Nine articles located Hip Hop as a culture. This included recognition of Hip Hop as originating in the Bronx, New York (DeCarlo \& Hockman, 2004) in the 1970s, among African American and Latino (Gonzalez \& Hayes, 2009) or inner-city youth (Boutin- 
Foster et al., 2010). Many also acknowledged the different elements of Hip Hop culture (Boutin-Foster et al., 2010; Emdin et al., 2016; Gonzalez \& Hayes, 2009; Harris et al., 2012; Sussman et al., 1995). These were described variously as b-boying/breaking/dance/movement, graffiti/tagging/art/visual art, DJing; MCing/rap/rapping, music/sound, dress/clothing style, language/slang, and knowledge of self. For Levy et al. (2017), this culture was also represented by the concept of the "cypher."

Some authors fore-fronted the socio-political nature of Hip Hop culture and its continuing relevance to US context. Emdin et al. (2016) described Hip Hop culture as representing "politically silenced voices in contemporary America, and [that] the process of writing/creating hip-hop music (rap) harnesses the voices of these populations to help them make sense of their everyday experiences and solve their own problems" (p. 310). Similarly, DeCarlo and Hockman (2004) suggested, despite negative perceptions (i.e. misogyny, violence, crime), rap/Hip Hop is the "conscious-raising voice of African American urban youth, addressing developmental issues as complex as identity and sociological concerns of racial inequality" (p. 46). Levy et al. (2017) further positioned hip-hop lyrics as providing under-resourced inner-city youth "a path to fighting back against a system that demonizes [them]" (p. 2). For Hill (2009) the texts of Hip Hop culture offer democratic and culturally relevant spaces for dialogue.

In the Australian context, Harris et al. (2012) described Hip Hop dance as part of street dance culture, alongside "techno" and "rave." Further, while these dance cultures are often associated with drugs and antisocial behaviour, "Australian hip hop culture [is] an opportunity for disadvantaged or ethnically diverse youth" (p. 240) to engage with social and personal philosophies and oral histories. Sussman et al. (1995) also locate Hip Hop as a "street culture" that was novel or appealing to young people. Paukste and Harris (2015) also described it as a street culture, yet more as element of the broader lifestyle of low-socioeconomic youth than connected to a historical or socio-political narrative.

\section{Hip Hop as activity, genre, or artform}

Six papers portrayed Hip Hop predominantly as a specific activity, artform, or genre. These descriptions were typically much briefer and included little or no reference to Hip Hop culture. Most described a type or genre of music, which has broad appeal among diverse youth, (Olson-McBride \& Page, 2012) with strong focus on dance and rhyme (Williams et al., 2016; Williams \& Noble, 2008) or particular elements like call and response, speed, and familiarity (Noble et al., 2015). Some descriptions were extremely brief, noting it only as a music type including digital sounds and communicating clear messages (Yoshida et al., 2013). Romero's (2012) description centered on break dancing "as dance moves set to hip hop beats; it requires a great degree of aerobic capability and strength to perform." (p.210)

\section{No formal description}

Seven papers offered no formal description of Hip Hop. Even when in the paper title, most simply mention an element of an intervention as being a Hip Hop workshop (McEwan et al., 2013), Hip Hop video (Lamb \& Randazzo, 2016; Tucker et al., 1999), or Hip Hop songs (Crouch et al., 2011), which were sometimes not distinguished from other songs in the study (Criss et al., 2016). Akintobi et al. (2011) did reference youth/ popular culture yet mention "hip-hop and rap" (p. 487) only briefly. One paper contained no reference to Hip Hop, except in the presentation of students' lyrics (Ennis et al., 2014).

\section{Rationale for using Hip Hop}

Rationales for using Hip Hop centred primarily on cultural relevance and ability to engage particular youth. In Australia, this included engaging low-socioeconomic and diverse youth in health promotion through an age appropriate (Crouch et al., 2011) and 
“culturally familiar milieu" (Harris et al., 2012, p. 239; Paukste \& Harris, 2015). US authors presented similar arguments, yet often drew more nuanced or developed connections. These inevitably included a desire to engage African American, Latino, or youth of Colour, given these populations are frequently exposed to the worst health stressors, yet are the least engaged with mainstream services or institutions (Levy et al., 2017) often because they represented or enacted oppression of these groups (Emdin et al., 2016; Hill, 2009). Many authors drew upon concepts and terms such as "culturally sensitive" (Sussman et al., 1995), "culturally targeted" (Williams et al., 2016), "culturally relevant" (Boutin-Foster et al., 2010) or "culturally appropriate" (Williams \& Noble, 2008). Some talked about the importance of creating links between students and facilitators in terms of providing "culturally similar role models" (Romero, 2012), "culturally sensitive instructors" (Akintobi et al., 2011), or using Hip Hop to "bridge cultural gaps" between students and facilitators (DeCarlo \& Hockman, 2004; Gonzalez \& Hayes, 2009). For music therapists that aim to use client-preferred music, it would seem that Hip Hop-informed programs provide an important way to connect with certain populations.

For others, Hip Hop presented opportunities to nurture "critical consciousness and activism" around topics of power, identity (Hill, 2009, p. 248) and discrimination (Romero, 2012), thus empowering students who may otherwise feel powerless in education contexts (Gonzalez \& Hayes, 2009). This often involved repositioning discourse and interventions within the context of students' daily lives and experiences (DeCarlo \& Hockman, 2004). Such authors drew on concepts like "critical pedagogy" (Hill, 2009), "reality pedagogy" (Emdin et al., 2016), as well as Hip Hop-specific theories, such as "critical Hip Hop pedagogy" (Romero, 2012), "Hip Hop-centered pedagogy," "hip-hop based education" (Hill, 2009, p. 248), "Hip Hop Therapy" (Olson-McBride \& Page, 2012) or "Rap therapy" (Gonzalez \& Hayes, 2009).

Some authors argued Hip Hop was used because the stylistic qualities of the music and dance (speed and strong beats) promoted learning outcomes (Noble et al. (2015). In contrast, several papers offered no clear rationale for the inclusion of Hip Hop. Of these, McEwan et al. (2013) stated simply the success of previous Hip Hop programs, while the rest made no mention of why Hip Hop was included, (Criss et al., 2016; Lamb \& Randazzo, 2016; Tucker et al., 1999) or of Hip hop at all (Ennis et al., 2014).

\section{Connection between Hip Hop and benefits}

Several accounts were offered for the relationship between Hip Hop and wellbeing. For many, Hip Hop provided a unique and culturally relevant "vehicle" or "medium" to deliver content (Boutin-Foster et al., 2010; Williams et al., 2016) or engage young people in an intervention or program (Harris et al., 2012; Paukste \& Harris, 2015). Here, while playing an important role, Hip Hop was sometimes considered to "supplement" (Williams \& Noble, 2008) the main intervention, which itself may not be directly related to Hip Hop culture. While many papers made compelling arguments regarding cultural relevance, they often positioned Hip Hop as a way to make health interventions more palatable or retain participation in other elements of a program (Akintobi et al., 2011). While such positions suggest Hip Hop has value in engaging youth in health interventions, we argue here that interventions taking this approach risk trivialising Hip Hop culture by relegating its role to a sweetener for the real work. These approaches may also be seen to support cultural appropriation.

Several articles described Hip Hop as not just a way to deliver content or engage students in healthy practices but as the origin of content or practices that themselves fostered wellbeing. This included identifying and promoting healthy behaviours and practices (such as breaking) within Hip Hop culture, and acknowledging that this culture involves critical engagement with narratives of social justice and awareness of the impact of privilege and discrimination (Romero, 2012). All authors reporting on therapeutic interventions also positioned Hip Hop as offering an alternate mode of being in the world (or therapeutic space) that connected with and valued the culture, identity, 
and socio-political reality of students (DeCarlo \& Hockman, 2004; Emdin et al., 2016). For Levy et al. (2017), this positioning meant offering students an alternative way to address mental health, given established approaches are rooted in, or founded upon, world views that traditionally exclude them. Gonzalez and Hayes (2009) extended on this notion, suggesting approaches that acknowledge and forefront students' affiliation and skills in Hip Hop (i.e. rapping) can reposition them as experts in a therapeutic relationship and "allow students to regain power in a situation where they may feel powerless" (p. 169). For Hill (2009), the texts of Hip Hop culture themselves (i.e. song lyrics) fostered student wellbeing, as they offer narratives that were more real, or reflective of students' own experiences where they could both see themselves and also connect to those around with similar narratives. Olson-McBride and Page (2012) extended on these ideas, suggesting Hip Hop texts allow students to engage in therapeutic work using their language, rather than the language of psychotherapy, which is unfamiliar to them. In all of these cases, Hip Hop provided not just a vehicle but a world view that acknowledged students' identity and empowered them to become agents in their own healing. These examples point to the wider value of engaging in Hip Hop as a therapist; not only does it provide a way to engage clients, it provides a unique space familiar to many young people in which they can engage in wellness work.

Several papers also highlighted the importance of involving artists and other members of the Hip Hop community to help develop (Sussman et al., 1995) and deliver content (Williams \& Noble, 2008) to ensure a level of authenticity. Involving active members of the Hip Hop community was also reported important for providing culturally relevant role models to reframe health behaviour norms (Romero, 2012; Williams et al., 2016). For Paukste and Harris (2015), learning from recognised Hip Hop artists was the key factor, as students were less involved when "rap artists" were not present. We argue that this illustrates both a potential challenge and opportunity in this area. These findings caution against the delivery of Hip Hop-informed programs without including members of the Hip Hop community. While the articles reviewed here discussed this concept specifically in relation to outcomes, we also caution that programs without a genuine connection to Hip Hop culture could not only appear inauthentic to clients but also risk cultural appropriation. Thus, we argue these findings clearly identify the value of engaging members of the Hip Hop community in any therapeutic program, either as co-facilitators, or at the very least, as paid consultants.

Some authors stated the particular stylistic attributes of Hip Hop supported wellbeing. Romero (2012) described the aerobic capabilities and strength necessary for breaking as beneficial for physical health, while Noble et al. (2015) suggested the call and response in rap helped reinforce concepts. Paukste and Harris (2015) suggested the "flow," or the interaction between rap lyrics and the rhythm of the beats, helped students engage with content in ways that other activities could not as they were considered undynamic, or "staid." Many papers provided minimal (Ennis et al., 2014) or no discussion of how Hip Hop led to outcomes (Criss et al., 2016; Crouch et al., 2011; Tucker et al., 1999).

\section{Methodological approaches}

\section{Quantitative}

Ten of the 22 papers focused on quantitative methods; nine of which were investigating a Health Awareness intervention and one which was investigating a Therapeutic Intervention. Sample sizes ranged from 21 (DeCarlo \& Hockman, 2004) to 717 (Sussman et al., 1995) students, with a mean of 228.55 across the 10 studies. Six studies used a pre-post design to measure change in their chosen construct of wellbeing (Lamb \& Randazzo, 2016; Noble et al., 2015; Romero, 2012; Sussman et al., 1995; Williams et al., 2016; Williams \& Noble, 2008). The other four collected data at one time-point only to assess constructs such as information retention (Tucker et al., 1999), program reach (Criss et al., 2016), song perception (Yoshida et al., 2013), affective response, 
prosocial skill acquisition, and preference for intervention method (DeCarlo \& Hockman, 2004).

Only four studies used a control or comparison group, while just half reported use of validated measures. While most papers stated at least some study limitations, several did not, and the reporting of standard statistical information, such as significance, was not consistent among studies. This information suggests that while quantitative methods have been used most consistently, there is a notable lack of studies in this area reporting with the methodological rigor typically expected of quantitative research.

\section{Qualitative}

Eight studies took qualitative approaches, including one ethnography (participant observation) with clear theoretical positioning and discussion of data collection (Hill, 2009). Another described a similar approach, yet also included interviews, artefacts, and clear positioning and transparent reporting of data collection and analysis (Emdin et al., 2016). Another used interviews and open ended surveys, and while the theoretical positioning was more basic, the methodology was clear and transparently reported (Harris et al., 2012).

Three papers reported program evaluations rather than research (Boutin-Foster et al., 2010; Ennis et al., 2014; McEwan et al., 2013). While these provided little to no detail on theoretical positioning, each provided notable detail on the methods and procedures. Two papers presented case studies or reflections on their work (Gonzalez \& Hayes, 2009; Levy et al., 2017). These papers were less focused on reporting research outcomes, and rather used vignettes or observations to support the presentation of particular program approaches.

The diversity in methodological rigor in these papers can largely be explained by the inclusion of published evaluation and case illustration papers in the review. For those that did take a research approach, reporting was of a high quality.

\section{Mixed Methods}

Four papers reported a combination of qualitative and quantitative-style approaches. One used focus groups and surveys to evaluate the impact of an intervention on changing attitudes to rape culture (Akintobi et al., 2011). While, again, this was an evaluation, descriptions for both processes of data collection and analysis were detailed and transparent, and measures were validated. Another studycoded video footage for instances of disclosure during therapy for quantitative analysis which compared two groups (Olson-McBride \& Page, 2012). These tapes were coded twice by two different people to check interrater reliability, and results were supported by interview data. Reporting was again clear and transparent.

Two papers reported evaluation-style approaches. One used observation data, focus groups, semi-structured interviews and a survey to evaluate impact of substance-use awareness program. Only descriptive statistics and basic thematic analysis were reported, although some description of methods was provided (Paukste \& Harris, 2015). The other used attendance data, testimonials, and what seemed like anecdotal data to assess the impact of sexual health workshops (Crouch et al., 2011). There was little to no discussion of data collection and no mention of analysis.

Again, the quality in these studies varied greatly, potentially due to the evaluative approach of the last two. Yet, while the first two reported reasonably rigorous studies, none of the four papers located themselves clearly in the methodological literature. The absence of engagement with discourse on mixed methods research was particularly notable, as was lack of discussion about how and when data from different approaches was combined. 


\section{Discussion and Conclusion}

Despite a steady increase in published research looking at the wellbeing benefits of Hip Hop in schools, studies in this area are limited. Research has focused predominately on engaging students in health promotion or prevention programs, or on delivering information about physical health, with results indicating Hip Hop presents significant potential for achieving positive outcomes.

Other studies explored Hip Hop-informed community development programs. These targeted health promotion but also reported benefits in areas of psychosocial wellbeing and community mobilisation. Several studies also investigated therapeutic approaches, reporting significant mental health outcomes. Connections to wider literature on the therapeutic benefits of Hip Hop is unmistakable, given interventions consistently followed, or were framed within, the work of key Hip Hop or and rap therapy theorists such as Don Elligan $(2004$; 2012) and the late Edgar Tyson (2002 ; 2004). This link to existing therapeutic discourse also signifies the relevance of this work to music therapy, as has previously been shown in texts such as Hadley and Yancy's (2012) Therapeutic uses of rap and hip hop.

Two studies also focused on pedagogical or curriculum-based programs. While these studies were fewer in number here, we recognise the enormous overlap with the sizeable Hip Hop education and critical pedagogy discourses (Ladson-Billings, 2015; Paris \& Alim, 2017; Petchauer, 2009). We acknowledge the porous boundaries between wellbeing and pedagogical programs and suggest mental health benefits reported in the two studies analysed here signify the enormous wellbeing potential of Hip Hopbased education programs and approaches.

Most research has taken place in the US, where both the rationale for using Hip Hop, and the mechanism credited for outcomes, relates predominantly to its ability to offer a culturally relevant way to engage students of Colour in urban settings. This focus is not surprising given Hip Hop culture originated within these US communities (Rose, 1994) and remains inextricably linked to their socio-political realities. Further, these populations have consistently been reported the most marginalised and at risk on wellbeing indicators.

Yet, considering the wealth of literature discussing the widespread adoption of Hip Hop culture around the globe (Mitchell, 2002; M. Morgan, 2016) it is puzzling that more studies from other countries were not identified ${ }^{4}$. The only other country with a related body of research is Australia where, again, studies have focused on using Hip Hop with communities of Colour - specifically remote Indigenous communities. Again, this is unsurprising given these populations have the lowest health indicators in the county, and, Hip Hop scholarship in Australia has almost exclusively focused on connections to Indigenous cultures and communities (Hutchings \& Crooke, 2017; Minestrelli, 2016; Mitchell, 2006; G. Morgan \& Warren, 2011; Warren \& Evitt, 2010).

It appears the standard of research rigor applied in this space (regardless of methodological approach) is still in development. It is also unclear which approaches are most relevant. Some argue for more rigorous quantitative designs, including randomisation, control groups (Boutin-Foster et al., 2010), and better measures (Lamb \& Randazzo, 2016; Olson-McBride \& Page, 2012) - which would undoubtedly conform with the dominant evidence-based paradigms of knowledge generation in health disciplines (Aigen, 2015). Yet, others argue such approaches are incapable of accounting for the centrality of culture in this work (Hill, 2009). Such claims seem solid given studies reviewed here overwhelming positioned culture as the key reason for using Hip Hopbased interventions, and the key facilitator of outcomes. Furthermore, within wider Hip Hop literature, many argue investigations of Hip Hop must critically engage with concepts of race, power, privilege, and colonialism (Rose, 1994), particularly in the contexts of education (Alim, 2007) wellbeing (Travis, 2016) and the research process (Marsh, 2012). Arguably, methodological paradigms that prioritise ethnographic and other qualitative methods, such as critical theory and participatory approaches, are most relevant to this area given their focus on subjectivity and the impact of systems 
on lived experience (Lincoln, Lynham, \& Guba, 2011). Conversely, positivist research approaches can often be seen to de-centre culture to maintain objectivity. We argue such objectivity risks an application or investigation of Hip Hop that uncouples it with its history and the socio-political narratives of resistance, anti-oppression, and anticolonialism the culture has championed over the last 40-plus years. The number of papers reviewed above that did not position Hip Hop as a culture, or in relation to these narratives, evidence the potential for this to occur in research. We concur with scholars who maintain academic literature must explicitly make such links in order to avoid compartmentalising discussions of Hip Hop from its cultural context (Rodriquez, 2006; Viega, 2016). Avoiding these links complies with discourse that justifies the appropriation of a culture that - as evidenced so strongly in the body of research reviewed above - exists to sustain, empower, and provide a voice for the marginalised communities in which it originated and continues to be practiced.

We hope the analysis provided here illustrates the potential of integrating Hip Hop into music and other creative arts therapies when working in school settings, as well as the need to conduct further research on such work. Further, we argue that the potential Hip Hop offers for engaging in social justice issues is invaluable not only for school settings but in society more generally. We also hope this paper illustrates necessary considerations which those from music therapy (or any other field) should be aware of if they decide to engage with Hip Hop in either practice or research.

\section{Acknowledgements}

Authors would like to acknowledge the Faculty of Fine Arts and Music at the University of Melbourne for supporting this project through the Faculty Small Grant Scheme.

\section{Disclosure Statement}

The authors report no potential conflicts of interest.

\section{About the authors}

Dr Alexander Hew Dale Crooke is Postdoctoral Research Fellow at the University of Melbourne. He is a transdisciplinary researcher who works across the fields of music therapy, social science, adolescent mental health, music education and cultural studies. His current research agenda centres on the benefits and challenges of school-based arts programs, focusing on issues of psychosocial wellbeing, research methodology, policy and contemporary youth culture.

Rachael Comte completed her Masters in Music Therapy at the University of Melbourne in 2015 and has since been working for Parkville College, a state school for students who are in custody, secure welfare or transitioning into the community from a custodial setting. Rachael has overseen the development of the music program for Parkville College at multiple sites; a role which entails the development and delivery of VET curriculum, in addition to coaching teachers through the use of therapeutic principles and practices when working with young people with experiences of trauma.

Cristina Moreno Almeida, PhD, is a British Academy Postdoctoral Fellow in the Department of Digital Humanities at King's College London. Her research is about culture, power, and resistance at the intersection of society, politics and digital media. She has published on music, youth culture, and digital media. Her current work analyses memes and digital cultures in Morocco. Her latest book is entitled Rap Beyond Resistance: Staging Power in Contemporary Morocco (Palgrave, 2017).

\section{Notes}

1. While commonly referred to as Laos, we have retained terminology used by the authors of the paper in question, as well as their associated abbreviation "Lao" elsewhere. 
2. While the dance element of Hip Hop culture is more commonly referred to as breaking or B-Girling/B-Boying, "dance" is used here given it was the term used most frequently in the reviewed papers.

3. The decision to refer to white with a lowercase ' $w$ ', while capitalising the first letter for other races/ethnicities, is an intentional move to decentre whiteness and aligns with moves from publications such as The Detroit Times in the US (DeVito, 2019).

4. We restrict this observation to English speaking countries

\section{References}

Aigen, K. (2015). A critique of evidence-based practice in music therapy. Music Therapy Perspectives, 33(1), 12-24, https://doi.org/10.1093/mtp/miv013.

*Akintobi, T. H., Trotter, J. C., Evans, D., Johnson, T., Laster, N., Jacobs, D., \& King, T. (2011). Applications in bridging the gap: A community-campus partnership to address sexual health disparities among African-American youth in the South. Journal of Community Health, 36(3), 486-494, https://doi.org/10.1007/s10900-010-9332-8.

Alim, H. S. (2007). Critical Hip-Hop language pedagogies: Combat, Consciousness, and the Cultural Politics of Communication. Journal of Language, Identity \& Education, 6(2), 161-176, https://doi.org/10.1080/15348450701341378.

*Boutin-Foster, C., McLaughlin, N., Gray, A., Ogedegbe, A., Hageman, I., Knowlton, C., \& Beeder, A. (2010). Reducing HIV and AIDS through prevention (RHAP): A theoretically based approach for teaching HIV prevention to adolescents through an exploration of popular music. Journal of Urban Health, 87(3), 440-451, https://doi.org/10.1007/ s11524-010-9435-7.

*Criss, S., Cheung, L. L., Giles, C., Gortmaker, S., Viswanath, K., Kwass, J. A., \& Davison, K. (2016). Media competition implementation for the Massachusetts childhood obesity research demonstration study (MA-CORD): Adoption and reach. International Journal of Environmental Research and Public Health, 13(4), 11, https://doi.org/10.3390/ ijerph13040403.

*Crouch, A., Robertson, H., \& Fagan, P. (2011). Hip hopping the gap - Performing arts approaches to sexual health disadvantage in young people in remote settings. Australasian Psychiatry, 19, S34-S37, https://doi.org/10.3109/10398562.2011.583046.

*DeCarlo, A., \& Hockman, E. (2004). RAP therapy a group work intervention method for urban adolescents. Social Work with Groups, 26(3), 45-59, https://doi.org/10.1300/ J009v26n03_06.

DeVito, L. (2019). Editor's note: Why we're capitalizing 'Black' from now on. Detroit Metro Times, Retrieved from https://www.metrotimes.com/detroit/editors-note-why-werecapitalizing-black-from-now-on/Content?oid $=21810658$.

Elligan, D. (2004). Rap therapy: A practical guide for communicating with youth and young adults through rap music. Kensington Books.

Elligan, D. (2012). Contextualizing rap music as a means of incorporating into psychotherapy. In S. Hadley \& G. Yancy (Eds.), Therapeutic uses of rap and hip-hop (pp. 27-38). Routledge.

*Emdin, C., Adjapong, E., \& Levy, I. (2016). Hip-hop based interventions as pedagogy/therapy in STEM A model from urban science education. Journal for Multicultural Education, 10(3), 307-321, https://doi.org/10.1108/jme-03-2016-0023.

*Ennis, G., Clark, H., \& Corfield, F. (2014). Adventure territory: An action evaluation of an Outback Australian performance project. Youth Theatre Journal, 28(2), 115-129, https://doi.org/10.1080/08929092.2014.932876.

Fitzgibbon, M. L., Stolley, M. R., Schiffer, L., Horn, L., KauferChristoffel, K., \& Dyer, A. (2006). Hip-Hop to health jr. for Latino preschool children. Obesity, 14(9), 1616-1625. 
*Gonzalez, T., \& Hayes, B. G. (2009). Rap Music in school counseling based on Don Elligan's rap therapy. Journal of Creativity in Mental Health, 4(2), 161-172, https://doi.org/10.1080/ 15401380902945293.

Greenhalgh, T., Robert, G., Macfarlane, F., Bate, P., Kyriakidou, O., \& Peacock, R. (2005). Storylines of research in diffusion of innovation: a meta-narrative approach to systematic review. Social Sciences and Medicine, 61, https://doi.org/10.1016/ j.socscimed.2004.12.001.

Hadley, S., \& Yancy, G. (2012). Therapeutic uses of rap and hip-hop. Routledge.

*Harris, N., Wilks, L., \& Stewart, D. (2012). HYPEd-up: Youth dance culture and health. Arts \& Health: International Journal for Research, Policy \& Practice, 4(3), 239-248, https://doi.org/ 10.1080/17533015.2012.677849.

*Hill, M. L. (2009). Wounded healing: Forming a storytelling community in hip-hop lit. Teachers College record, 111(1), 248.

Hill, M. L., \& Petchauer, E. (2013). Schooling hip-hop: Expanding hip-hop based education across the curriculum. Teachers College Press.

Hutchings, S., \& Crooke, A. H. D. (2017). The use of Hip Hop by Indigenous Australian artists to celebrate traditional cultural identity and increase social awareness (Paper presented at the MUSICULT '17 / IV. International Music and Cultural Studies Conference, Istanbul, Turkey).

Johnson-Baker, K. A., Markham, C., Baumler, E., Swain, H., \& Emery, S. (2016). Rap music use, perceived peer behavior, and sexual initiation among ethnic minority youth. Journal of Adolescent Health, 58(3), 317-322, https://doi.org/10.1016/j.jadohealth.2015.11.003.

Ladson-Billings, G. (2015). You gotta fight the power: The place of music in social justice Education. In P. Benedict, P. Schmidt, G. Spruce, \& P. Woodford (Eds.), The Oxford handbook of social justice in music education (pp. 406-419). Oxford University Press.

*Lamb, S., \& Randazzo, R. (2016). An examination of the effectiveness of a sexual ethics curriculum. Journal of Moral Education, 45(1), 16-30, https://doi.org/10.1080/ 03057240.2016.1156520.

*Levy, I., Emdin, C., \& Adjapong, E. S. (2017). Hip-Hop cypher in group work. Social Work with Groups, 1, 1-8, https://doi.org/10.1080/01609513.2016.1275265.

Lincoln, Y. S., Lynham, S. A., \& Guba, E. G. (2011). Paradigmatic controversies, contradictions, and emerging confluences, revisited. In N. K. Denzin \& Y. S. Lynham (Eds.), The Sage handbook of qualitative research (4th ed., pp. 97-128). SAGE Publications Inc.

Marsh, C. (2012). Hip Hop as methodology: Ways of knowing. Canadian Journal of Communication, 37(1), 193.

*McEwan, A., Crouch, A., Robertson, H., \& Fagan, P. (2013). The Torres Indigenous Hip Hop project: Evaluating the use of performing arts as a medium for sexual health promotion. Health Promotion Journal of Australia, 24(2), 132-136, https://doi.org/10.1071/HE12924.

Minestrelli, C. (2016). Australian Indigenous Hip Hop: The politics of culture, identity, and spirituality. Routledge.

Mitchell, T. (2006). Blackfellas rapping, breaking and writing: A short history of Aboriginal hip hop. Aboriginal History, 30, 124-137.

Mitchell, T. (2002). Global noise: Rap and Hip Hop outside the USA. Wesleyan University Press.

Morgan, G., \& Warren, A. (2011). Aboriginal youth, hip hop and the politics of identification. Ethnic and Racial Studies, 34(6), 925-947, https://doi.org/10.1080/ 01419870.2010 .517323$.

Morgan, M. (2016). 'The world is yours': The globalization of Hip-Hop language. Social identities, 22(2), 133-149.

*Noble, J. M., Hedmann, M. G., \& Williams, O. (2015). Improving dementia health literacy using the FLOW Mnemonic: Pilot findings from the old SCHOOL Hip-Hop program. Health education \& Behavior, 42(1), 73-83, https://doi.org/10.1177/1090198114537063. 
*Olson-McBride, L., \& Page, T. F. (2012). Song to self: Promoting a therapeutic dialogue with high-risk youths through poetry and popular music. Social Work with Groups, 35(2), 124-137, https://doi.org/10.1080/01609513.2011.603117.

Paris, D., \& Alim, H. S. (2017). Culturally sustaining pedagogies: Teaching and learning for justice in a changing world. Teachers College Press.

*Paukste, E., \& Harris, N. (2015). Using rap music to promote adolescent health: Pilot study of VoxBox. Health Promotion Journal of Australia, 26(1), 24-29, https://doi.org/10.1071/ HE14054.

Petchauer, E. (2009). Framing and reviewing Hip-Hop educational research. Review of Educational Research, 79(2), 946-978.

Popay, J., Roberts, H., Sowden, A., Petticrew, M., Arai, L., Rodgers, M., \& Duffy, S. (2006). Guidance on the conduct of narrative synthesis in systematic reviews. A product from the ESRC methods programme Version, 1, b92.

Rodriquez, J. (2006). Color-blind ideology and the cultural appropriation of Hip-Hop. Journal of Contemporary Ethnography, 35(6), 645-668, https://doi.org/10.1177/ 0891241606286997.

* Romero, A. J. (2012). A pilot test of the Latin active Hip Hop intervention to increase physical activity among low-income Mexican-American adolescents. American Journal of Health Promotion, 26(4), 208-211, https://doi.org/10.4278/ajhp.090123-ARB-24.

Rose, T. (1994). Black noise: Rap music and black culture in contemporary America. Wesleyan Univesrity Press.

Seidel, S. (2011). Hip Hop genius: Remixing high school education. R\&L Education.

Shochet, I. M., Dadds, M. R., Holland, D., Whitefield, K., Harnett, P. H., \& Osgarby, S. M. (2001). The efficacy of a universal school-based program to prevent adolescent depression. Journal of Clinical Child \& Adolescent Psychology, 30(3), 303-315, https://doi.org/10.1207/ S15374424JCCP3003_3.

*Sussman, S., Parker, V. C., Lopes, C., Crippens, D. L., Elder, P., \& Scholl, D. (1995). Empirical development of brief smoking prevention videotapes which target African-American adolescents. International Journal of the Addictions, 30(9), 1141-1164, https://doi.org/ 10.3109/10826089509055832.

Tanner, J., Asbridge, M., \& Wortley, S. (2009). Listening to rap: Cultures of crime, cultures of resistance. Social Forces, 88(2), 693-722.

Thompson, W. R. (2009). After-school all-stars: Providing structured health and physical activity programs in urban environments. Journal of Physical Education, Recreation \& Dance, 80(8), 32-34, https://doi.org/10.1080/07303084.2009.10598373.

Travis, R. (2016). The healing power of Hip Hop. ABC-CLIO.

*Tucker, J. B., Barone, J. E., Stewart, J., Hogan, R. J., Sarnelle, J. A., \& Blackwood, M. M. (1999). Violence prevention: Reaching adolescents with the message. Pediatric Emergency Care, 15(6), 436-439, https://doi.org/10.1097/00006565-199912000-00019.

Tyson, E. H. (2002). Hip hop therapy: An exploratory study of a rap music intervention with at-risk and delinquent youth. Journal of Poetry Therapy, 15(3), 131-144.

Tyson, E. H. (2004). Rap music in social work practice with African-American and Latino youth. Journal of Human Behavior in the Social Environment, 8(4), 1-21, https://doi.org/ 10.1300/J137v08n04_01.

Viega, M. (2016). Exploring the discourse in Hip Hop and implications for music therapy practice. Music Therapy Perspectives, 34(2), 138-146, https://doi.org/10.1093/mtp/ miv035.

Warren, A., \& Evitt, R. (2010). Indigenous Hip-Hop: overcoming marginality, encountering constraints. Australian Geographer, 41(1), 141-158, https://doi.org/10.1080/

00049180903535659. 
*Williams, O., DeSorbo, A., Sawyer, V., Apakama, D., Shaffer, M., Gerin, W., \& Noble, J. (2016). Hip Hop HEALS: Pilot Study of a culturally targeted calorie label intervention to improve food purchases of children. Health Education \& Behavior, 43(1), 68-75, https://doi.org/10.1177/1090198115596733.

*Williams, O., \& Noble, J. M. (2008). 'Hip-Hop' stroke - A stroke educational program for elementary school children living in a high-risk community. Stroke, 39(10), 2809-2816, https://doi.org/10.1161/strokeaha.107.513143.

*Yoshida, I., Kobayashi, T., Sapkota, S., \& Akkhavong, K. (2013). A scale to evaluate music for health promotion in Lao PDR: Initial development and assessment. Arts \& Health: International Journal for Research, Policy \& Practice, 5(2), 120-131, https://doi.org/ 10.1080/17533015.2012.736395. 